\title{
Identification of Intronic Point Mutations as an Alternative Mechanism for p53 Inactivation in Lung Cancer
}

Takashi Takahashi, Domenico D'Amico, Itsuo Chiba, Dorothy L. Buchhagen, and John D. Minna

National Cancer Institute-Navy Medical Oncology Branch, National Cancer Institute, and Uniformed Services University

of the Health Sciences, Bethesda, Maryland 20814

\section{Abstract}

The p53 gene initially was thought to be an oncogene, but recent evidence suggests that wild-type p53 can function as a tumor suppressor gene in lung, colon, and breast caincer as well as less common malignancies. This study reports the first identification of intronic point mutations as a mechanism for inactivation of the p53 tumor suppressor gene. Abnormally sized p53 mRNAs found in a small cell and a non-small cell lung cancer cell line were characterized by sequence analysis of cDNA/PCR products, the RNase protection assay and immunoprecipitation. These mRNAs were found to represent aberrant splicing leading to the production of abnormal or no p53 protein. Sequence analysis of genomic DNA revealed that a point mutation at the splice acceptor site in the third intron or the splice donor site in the seventh intron accounts for the abnormal mRNA splicing. In one patient the same intronic point mutation was found in the tumor cell line derived from a bone marrow metastasis and in multiple liver metastases but not in normal DNA, indicating that it occurred as a somatic event before the development of these metastases. These findings further support the role of inactivation of the $\mathrm{p53}$ gene in the pathogenesis of lung cancer and indicate the role of intronic point mutation in this process. (J. Clin Invest. 1990. 86:363369). Key words: tumor suppressor gene $\bullet$ recessive oncogene • abnormal splicing

\section{Introduction}

Recently, several lines of evidence have indicated that the wild-type p53 gene is able to act as a tumor suppressor gene and that a mutant p53 gene could promote transformation by inactivating normal p53 function in a dominant negative fashion $(1,2)$. The first evidence of $\mathrm{p} 53$ inactivation was observed in Friend virus-induced mouse erythroleukemia in which inactivation results from rearrangement of the murine $\mathrm{p} 53$ gene (3). Frequent allele loss of chromosome region 17p13 (4-6), on which the human p53 gene resides, led to the discovery of p53 abnormalities in various human tumors. DNA rearrangements have been reported in human tumors, such as osteosarcoma, lung cancer and chronic myelocytic leukemia (7-9). In

Address reprint requests to Dr. Minna, NCI-NMOB, Building 8, Room 5101, Naval Hospital Bethesda, Bethesda, MD 20814.

Received for publication 26 February 1990 and in revised form 6 April 1990.

The Journal of Clinical Investigation, Inc.

Volume 86, July 1990, 363-369 addition to gross DNA abnormalities, a number of different point mutations in the highly conserved region of the open reading frame has been observed in a variety of common cancers, such as lung, colon, and breast cancer $(5,8,10)$.

In previous studies, we observed abnormally sized p53 mRNAs in lung cancer without any gross p53 DNA alterations (8). In an effort to understand the mechanism by which these abnormal mRNAs are generated, we analyzed both their cDNAs and genomic DNAs and found intronic point mutations leading to aberrant mRNA splicing. This resulted in production of a truncated or no p53 protein, representing an alternative mechanism for $\mathrm{p} 53$ inactivation.

\section{Methods}

Cell lines, tumor, and normal specimens. H526 is a small cell lung cancer (SCLC) ${ }^{1}$ cell line established from a bone marrow metastasis of patient 526 at the time of diagnosis. $\mathrm{H647}$ is an adenosquamous cell lung cancer cell line. BL7 and BL1436 are normal B-lymphocyte cell lines established from SCLC patients and were used as normal controls for sequencing analyses. H23 is a lung adenocarcinoma cell line which has a point mutation at codon 246 and was used in immunoprecipitations as a control for normally sized p53. Derivation and culture of these cell lines have been reported $(11,12)$. DNA and RNA were prepared as described (13). DNAs were extracted also from normal liver, normal kidney, and three different liver metastases of patient 526 at the time of autopsy.

Amplification and sequencing of cDNA using polymerase chain reaction (PCR). First strand cDNA synthesis using 5-10 $\mu \mathrm{g}$ of total cellular RNA with p53 specific oligonucleotide primers and subsequent PCR amplification were performed as previously described (8). Primers were prepared using a 380B DNA synthesizer (Applied Biosystems, Foster City, CA). All primers had extraneous nucleotides comprising Eco RI sites at their $5^{\prime}$ ends. Using the nucleotide numbers of the sequence published by Lane and Crawford as reference points (14), the sense primers used for CDNA/PCR were: S1, nt439 to 458; S2, nt540 to 563 ; S4, nt1137 to 1160 ; and S4, nt 1344 to 1361 . The antisense primers for cDNA/PCR were: AS1, nt1 170 to 1193; AS2, nt1740 to 1763 ; and AS3, nt2821 to 2844 . PCR amplification was performed for 30 cycles of $94^{\circ} \mathrm{C}(1 \mathrm{~min}), 55^{\circ} \mathrm{C}(1 \mathrm{~min})$ and $72^{\circ} \mathrm{C}(3 \mathrm{~min})$ followed by a 10 -min extension at the end. Amplification was followed by digestion with Eco RI and agarose gel electrophoresis. Purified fragments (Geneclean; Bio 101, La Jolla, CA) were cloned into the Eco RI site of pcDNA I (Invitrogen). These fragments were sequenced with the GemSeq K/RT system (Promega Biotec, Madison, WI). Direct se-

1. Abbreviations used in this paper: Full designation of the cell lines includes the prefix "NCF."; SCLC, small cell lung cancer; PCR, polymerase chain reaction; RFLP, restriction fragment length polymorphism. 
A
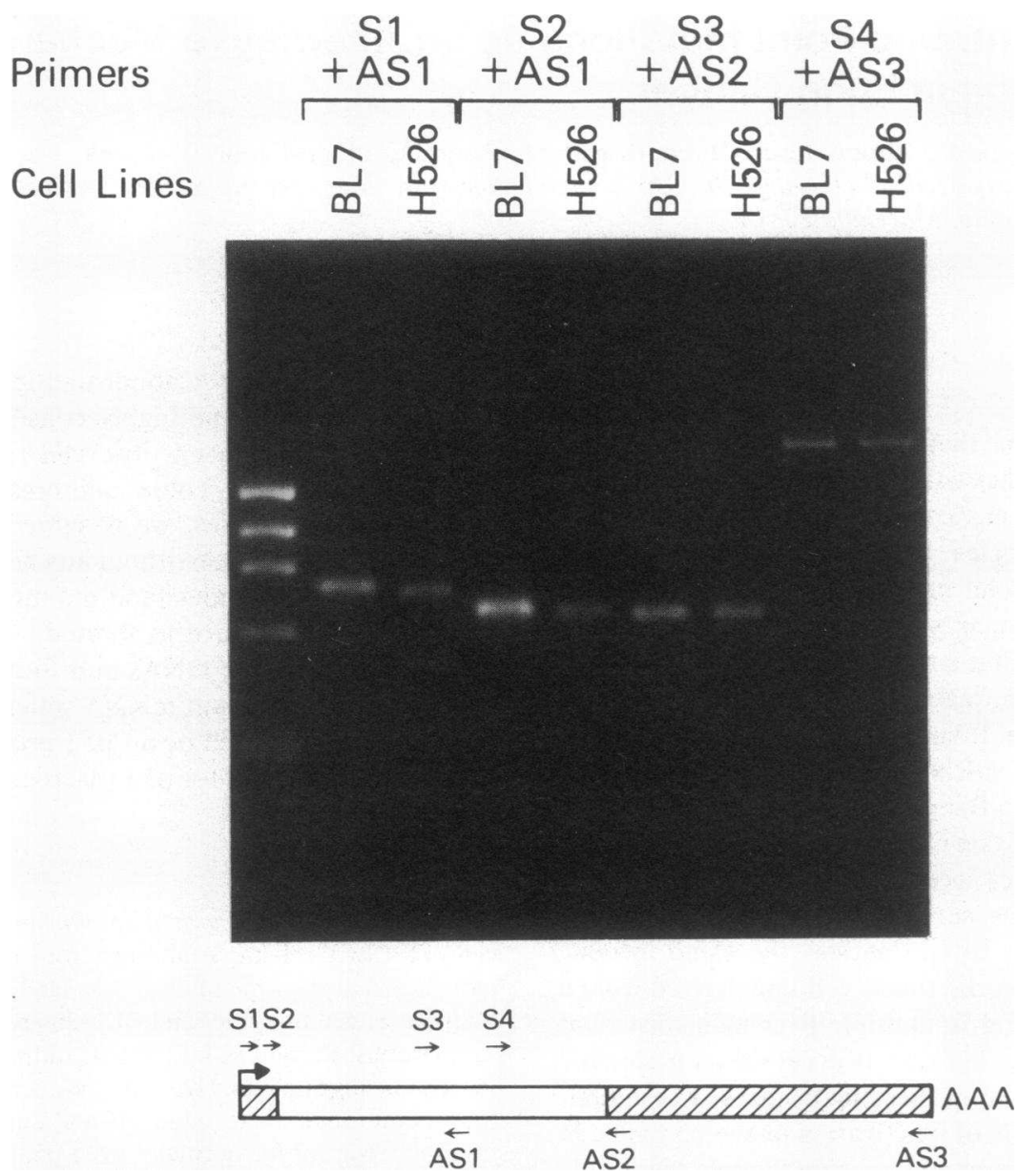

B

Normal

Exon 3

Exon 4

Exon 5

..-Leu Ser-.4aa-Gin Ala Met Asp Asp Leu Met... 80 a a... Thr Tyr Ser...

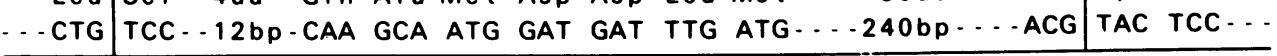

H526

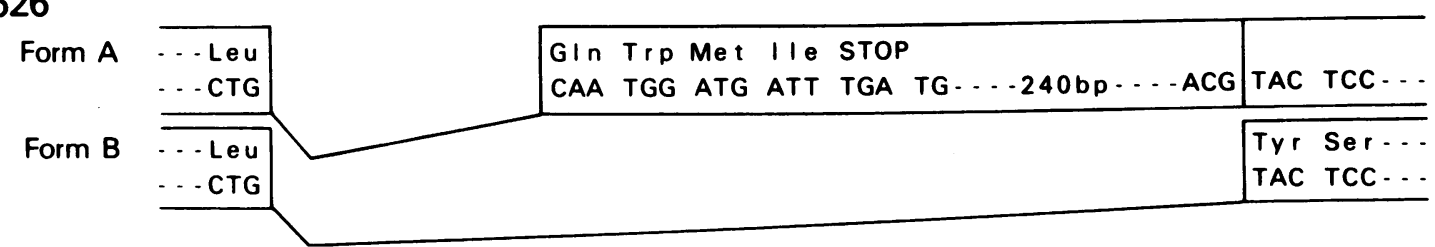

C

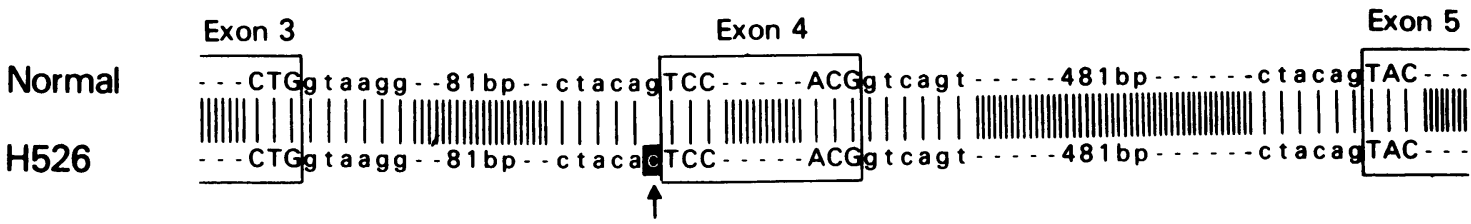


quencing of the CDNA/PCR products was also employed to confirm the identified abnormalities using $\left[{ }^{35} \mathrm{~S}\right] \mathrm{dATP}$ and the Sequenase kit (U.S. Biochemical Corp., Cleveland, $\mathrm{OH}$ ).

Amplification and sequencing of genomic DNA using PCR. PCR amplification was performed using 1-2 $\mu \mathrm{g}$ of genomic DNA and the same cycles as those for $\mathrm{CDNA} / \mathrm{PCR}$ after denaturation at $94^{\circ} \mathrm{C}$ for 5 $\mathrm{min}$. Three sets of primers were used for genomic DNA/PCR: intron 2 and intron 3 including exon 3, nt606 to 629 and nt633 to 646 ; intron 4, nt906 to 929 and nt942 to 965 ; and intron 7, nt1299 to 1322 and nt 1353 to 1370 . All primers had extraneous nucleotides comprising Eco RI sites at their 5 ' ends. The PCR products were cloned into pGEM4 (Promega Biotec) as described above. Direct sequencing of genomic DNA/PCR was also used to confirm the identified mutations as described above.

RNase protection assay. An anti-sense RNA probe (p53XP) was synthesized using [ $\left.{ }^{32} \mathrm{P}\right] \mathrm{UTP}$ and hybridized to $10 \mu \mathrm{g}$ of total cellular RNA at $58^{\circ} \mathrm{C}$ followed by digestion with RNase $\mathrm{A}(40 \mu \mathrm{g} / \mathrm{ml})$ at $30^{\circ} \mathrm{C}$ for $30 \mathrm{~min}$. The protected fragments were analyzed by denaturing polyacrylamide gel electrophoresis as described (8). After appropriate exposure of the films, densitometric analysis was performed using a scanning densitometer (model GS300; Hoefer).

Immunoprecipitation. All cell lines were labeled with $\left[{ }^{35}\right.$ S $]$ methionine for $1 \mathrm{~h}$ and cell extracts were prepared as described (15). Aliquots containing equal amounts of TCA-insoluble radioactivity were first precleared, incubated with anti-P53 monoclonal antibodies or a control MAb, MOPC21, and then immunoprecipitated using protein ASepharose, which was followed by SDS-polyacrylamide gel electrophoresis on a $10 \%$ gel essentially as described (15). Anti-p53 monoclonal antibodies used were PAb 1801 (Oncogene Science, Manhasset, NY) (16) and PAb421 (17) (kindly provided by M. Oren, The Weizmann Institute of Science, Rehovot, Israel). Amino acid residues containing the epitopes recognized by PAb1801 and PAb421 are 32 to 79 and 370 to 386 , respectively $(16,18)$.

\section{Results}

Structural analysis of p53 mRNA from $H 526$ by cDNA/PCR. Analysis by agarose gel electrophoresis of the cDNA/PCR products of the $\mathrm{p} 53$ gene expressed in the $\mathrm{H} 526$ cell line using a panel of oligonucleotide primers showed an anomalous fragment with either S1 and AS1 or S2 and AS1 migrating at a smaller molecular size in addition to the presumably normally sized fragment. Primers S2 and AS2 were used to clone the entire coding region of the p53 gene. Sequence analysis revealed two different species of cDNA clones, both of which were found to be mutant (Fig. $1 B$ ). Form A has a 19-bp deletion within exon 4 , although this form was recovered from the cDNA/PCR products as an apparently normally sized fragment. This deletion shifts the reading frame and results in a TGA termination codon 13 bases downstream. The predicted truncated protein would contain only 36 amino acids (which is 9\% of normal p53). Form B is missing the entire exon 4. This deletion eliminates 93 amino acids but does not alter the reading frame. No normal p53 cDNA clone was identified. These results were confirmed by the separate, direct sequencing of the two fragments shown in Fig. $1 \mathrm{~A}$.

Structural analysis of genomic DNA from H526. Since these cDNA mutants were highly suggestive of an abnormal
mRNA splicing event, we searched the genomic DNA for a mutation to explain the aberrant mRNAs. We amplified and sequenced intron 3 and intron 4 in addition to the surrounding genomic regions of the $\mathrm{p} 53$ gene in $\mathrm{H} 526$. A point mutation in the splice acceptor site at the $5^{\prime}$ end of exon 4 was found (Fig. 1 $C)$. This intronic point mutation converts a splice acceptor sequence, 5'-CTAC $A G-3^{\prime}$, into the sequence $5^{\prime}-\mathrm{CTAC} A C-3^{\prime}$ (Fig. $1 C$ ). The point mutation appears to abolish normal splicing at this site which results in complex abnormal splicing. Instead, in form A a cryptic splice acceptor site (5'-CCCAAG$3^{\prime}$ ), which is located the most $5^{\prime}$ among those in exon 4 , is utilized to generate form A mRNA. In form B the normal splice acceptor site at the $5^{\prime}$ end of exon 5 is used resulting in the fusion of exon 3 directly to exon 5 .

We also note that an $A$ instead of a $G$ was found $4 \mathrm{bp}$ upstream from the $5^{\prime}$ end of exon 5 , differing from the published sequence by Buchman et al (19). Of interest, since an A was observed in three independent individuals (two normal DNAs and one lung cancer DNA), the G in the RP kidney cancer cell line described by Buchman et al. may represent either a restriction fragment length polymorphism (RFLP) or an intronic point mutation.

$R$ Nase protection assay. Since the cDNA/PCR procedure is not quantitative, we wished to know the ratio of form $A$ to $B$ mRNA. Using the anti-sense $\mathrm{p} 53 \mathrm{XP}$ probe, the RNase protection assay revealed that form $A$ is the major species of abnormally sized mRNAs expressed (Fig. 2). Form $A$ is expressed in amounts at least 10 times higher than form $B$ as determined by densitometric tracing which was adjusted for the number of $U$ residues in the protected fragments.

Analysis of constitutional and tumor DNA from patient 526. We next wished to know if this intronic point mutation occurred in the patient and if this was a germline or a somatic mutation. DNAs extracted from normal liver, normal kidney and three different liver metastases harvested at the time of necropsy were subjected to genomic DNA/PCR and direct sequencing analyses (Fig. 3). The mutant splice acceptor site sequence but no example of normal p53 sequence was detected in all three tumor deposit DNAs and the H526 cell line DNA, whereas no mutations were found in DNAs from normal cells. Thus, this mutation appears to have occurred in the patient as a somatic event and seems to be hemi- or homozygous in the genome of the tumors.

Structural analysis of $m R N A$ and genomic DNA from $H 647$ by PCR. Fig. $4 A$ shows agarose gel electrophoresis of the cDNA/PCR products of the lung adenocarcinoma cell line, H647, and the normal B-lymphocyte line, BL7. The cDNA/ PCR products of $\mathrm{H} 647$ generated by primers S3 and AS2 yielded a fragment of larger molecular size than that of BL7. cDNA containing the entire p53 coding region was cloned using primers S2 and AS2 and sequenced. A 344-bp insertion in the coding sequence was identified between exon 7 and exon 8. This incorporation of an extraneous sequence resulted in the addition of 20 amino acids to the $3^{\prime}$ end of exon 7 followed by a TGA termination codon. Therefore, this termi-

Figure 1. Structural analysis of mRNA and genomic DNA of the p53 gene in the H526 cell line. $(A)$ cDNA/PCR products using a panel of oligonucleotides were analyzed by agarose gel electrophoresis. Molecular marker is Hae III digested PhiX174 DNA. Schematic diagram of p53 including location of oligonucleotides is shown below. The cDNA/PCR products primed with either S1 and AS1 or S2 and AS1 show an anomalous fragment of a smaller size in addition to the presumably normally sized fragment. $(B)$ Sequence analysis of cDNA/PCR products yields two different species of abnormally spliced mRNA forms. $(C)$ Sequence analysis of genomic DNA/PCR reveals intronic point mutation at the splice acceptor site at $5^{\prime}$ end of exon 4 . 


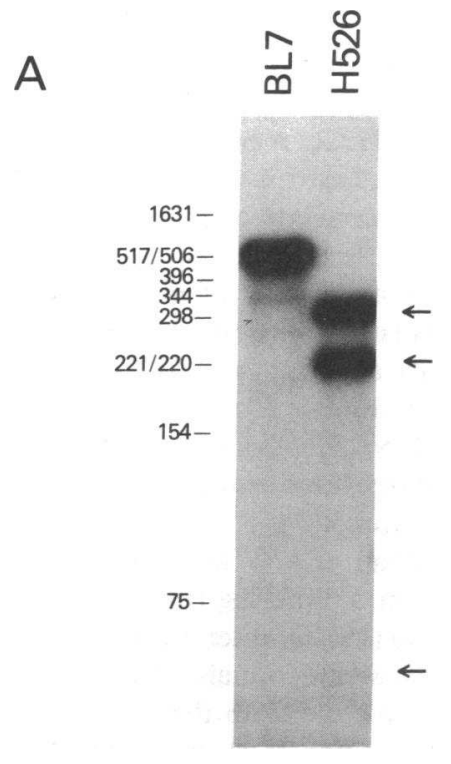

B

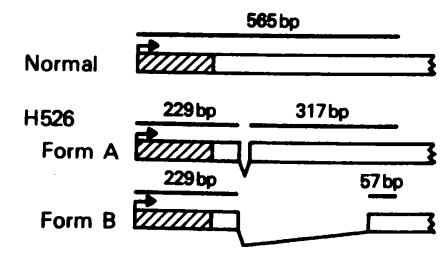

Figure 2. RNase protection assay of $\mathrm{H} 526$ cell line mRNA. ( $A$ ) Using the anti-sense p53XP RNA probe, the RNase protection assay shows that form A, which utilizes a cryptic splice acceptor site in exon 4 , is the major species of abnormally spliced mRNAs. Upper arrow indicates 317-bp fragment protected by A; middle arrow, 229-bp fragment protected by both forms A and B; lower arrow, 57-bp fragment protected by $B$. (B) Schematic diagram of the results as well as that of p53 mRNA and the anti-sense p53XP probe is shown.

nation signal eliminates exons 8 through 11 in the coding region of $\mathrm{H647}$ and translation of this message would result in a truncated product of 281 amino acids.

An intronic point mutation responsible for this abnormality was identified by genomic DNA/PCR of intron 7 and its surrounding region (Fig. $4 \mathrm{~B}$ ). A splice donor sequence, $5^{\prime}$ GTCAGG-3', was mutated into the sequence, 5'-TTCAGG-3' (Fig. $4 C$ ), resulting in retention of the entire intron 7 sequence

in the mRNA of H647. No normal allele was recovered indicating that this mutation is hemi- or homozygous in the genome of H647. These results were confirmed by direct sequencing of the cDNA/PCR and the genomic DNA/PCR products.

Analysis of the p53 product by immunoprecipitation. In order to analyze the p53 gene product of aberrant mRNAs that we had detected, H526, H647, and H23 cells were labeled metabolically with $\left[{ }^{35} \mathrm{~S}\right]$ methionine and lysates were prepared and subjected to immunoprecipitation (Fig. 5). H23 which had been shown to contain a point mutation at codon 246 served as a normally sized p53 control for both PAb1801 and PAb421 MAbs. As expected from the sequence analysis of $\mathrm{H} 526$ cDNAs, the p53 gene product of H526 lacks the PAb1801 antigenic determinant(s) encoded by exon 4 sequences. However, PAb421 recognizes the truncated product (molecular weight $40 \mathrm{kD}$ ), which is the size predicted from the form $B$ abnormally spliced mRNA. In contrast to H526, no detectable product of the p53 gene was immunoprecipitated from cell lysates of $\mathrm{H} 647$ with either of the MAbs, although the predicted product of $\mathrm{H} 647$ contains the PAb1801 epitope but lacks the PAb421 epitope. Absence of the p53 gene product in H647 was confirmed also by immunocytochemistry using these same MAbs (data not shown).

\section{Discussion}

There is now good evidence that p53 mutations are involved in the pathogenesis of human cancers $(5,7-10)$. The p53 mutations reported so far include gross DNA changes, such as homozygous deletions (8) and rearrangements (7-9), and point mutations which result in amino acid substitutions $(5,8,10)$. The present work extends our understanding of the mechanism leading to p53 abnormalities. Here, we show for the first time that intronic point mutations can serve as an alternative mechanism for $\mathrm{p} 53$ inactivation.

In SCLC cell line H526, an intronic point mutation at the splice acceptor site leads to two abnormally spliced mRNAs.

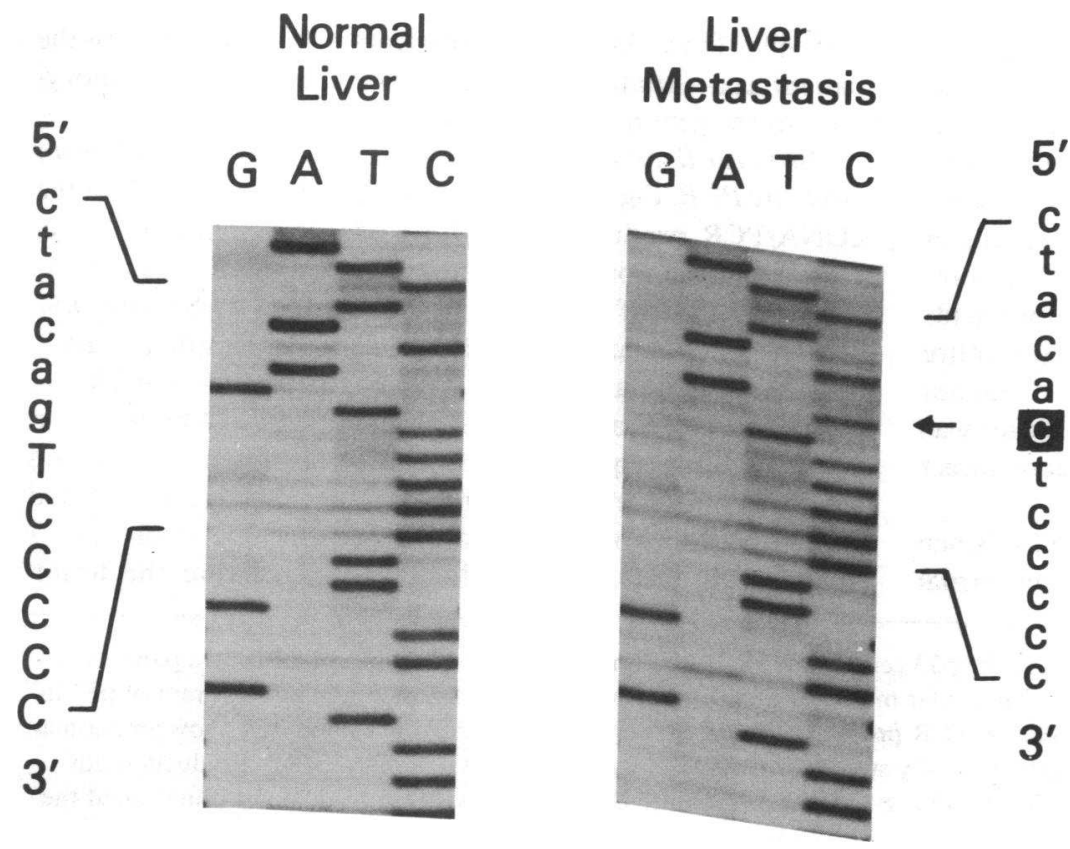

Figure 3. Analysis of constitutional and tumor DNAs from patient 526 . Only the mutant splice acceptor site sequence is detected in tumor DNA, whereas no mutations are found in DNA from normal cells. 

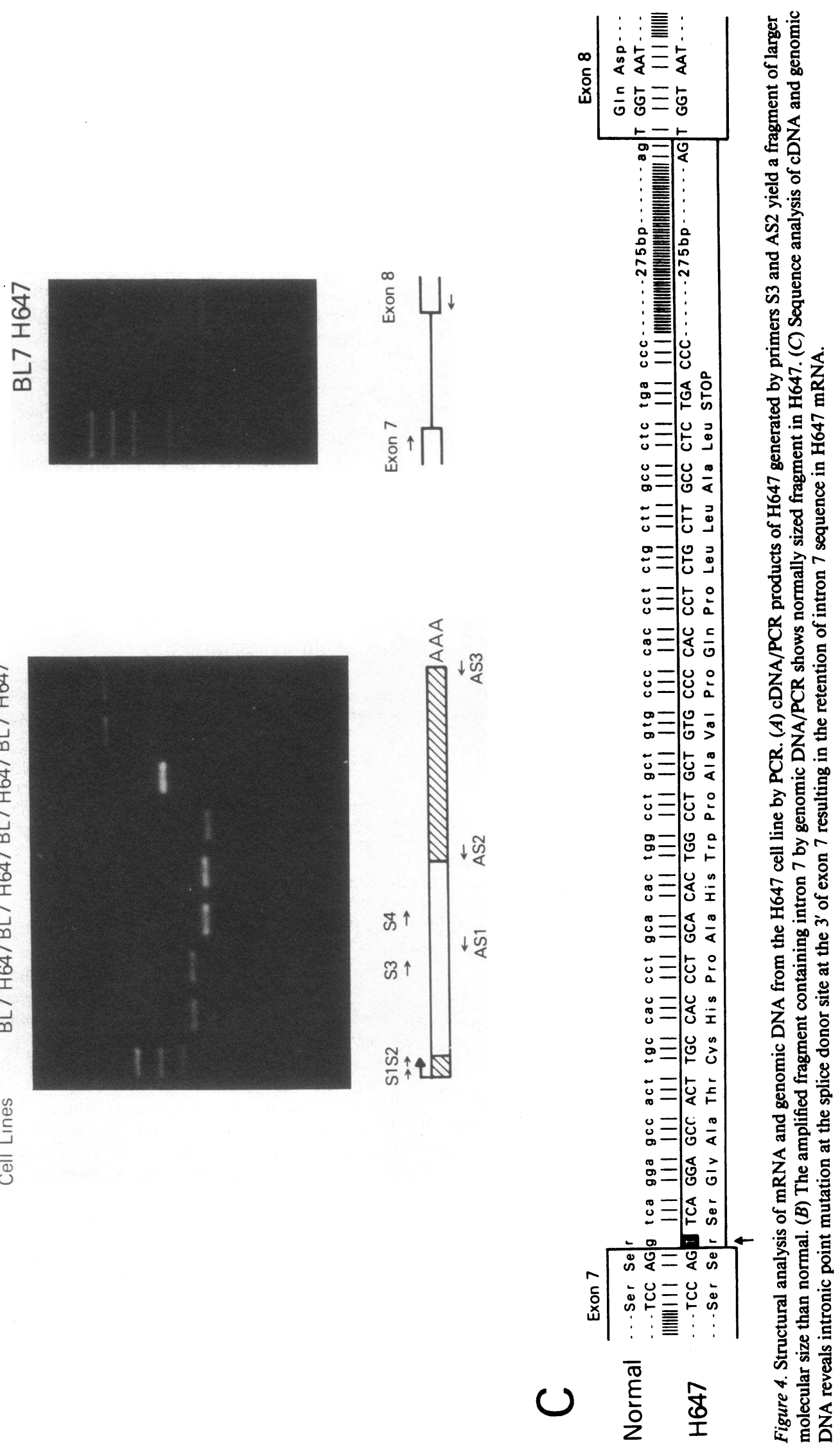


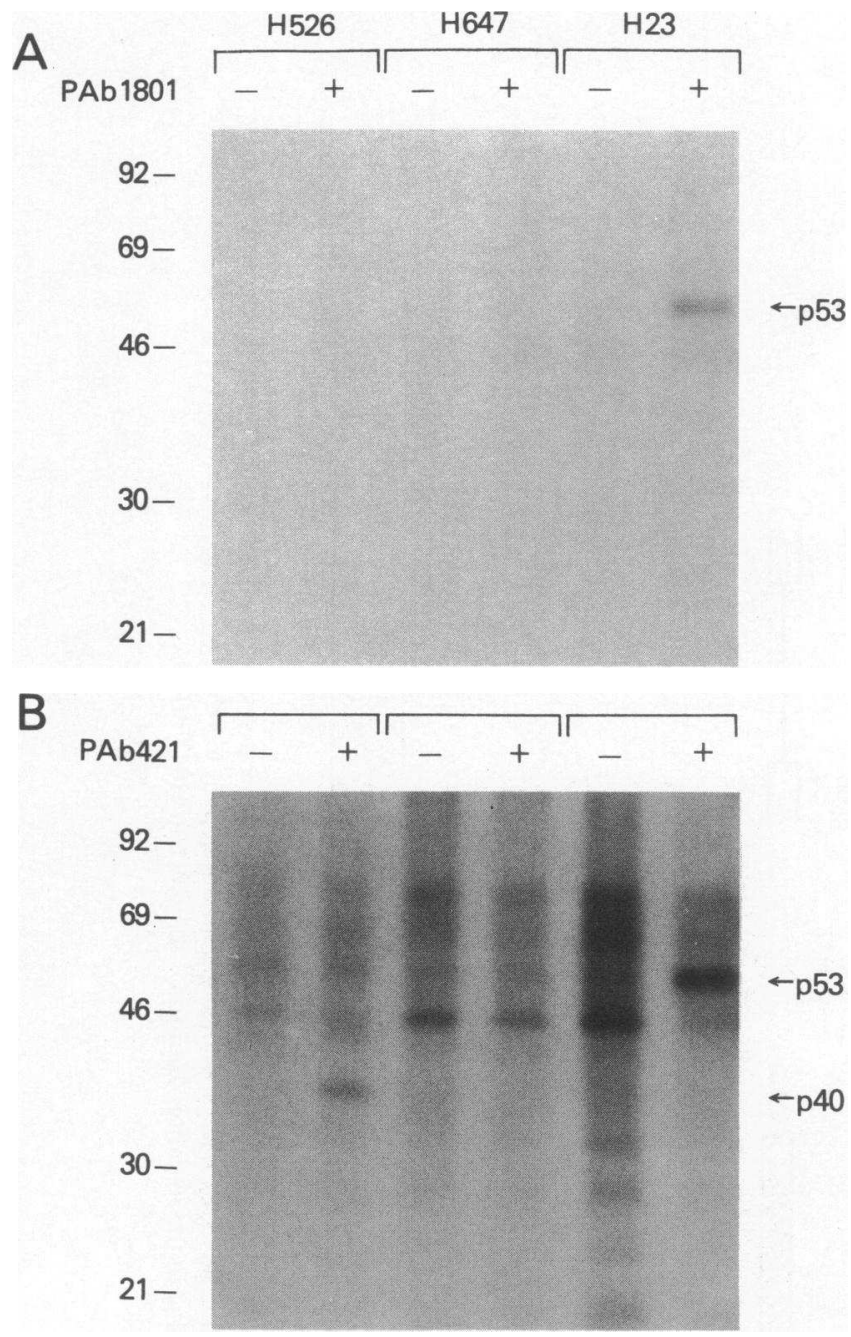

Figure 5. Analysis of p53 products by immunoprecipitation. H526, $\mathrm{H} 647$, and $\mathrm{H} 23$ cells were labeled metabolically with $\left[{ }^{35}\right.$ S $]$ methionine and subjected to immunoprecipitation analyses using PAb1801 $(A)$ and PAb421 $(B)$ monoclonal antibodies. $(A)$ PAb1801 immunoprecipitates p53 in $\mathrm{H} 23$, but not in $\mathrm{H} 526$ or in H647. (B) PAb421 immunoprecipitates a smaller protein (p40) in $\mathrm{H} 526$ and normally sized protein in $\mathrm{H} 23$, whereas no $\mathrm{p} 53$ product was detected in $\mathrm{H} 647$.

In form $\mathrm{A}, \mathrm{a}$ 19-bp deletion within exon 4 shifts the reading frame and results in premature termination eliminating $91 \%$ of the amino acids from the p53 gene product. Form B is missing the entire exon 4 resulting in the truncated $\mathrm{p} 53$ protein (p40) which has lost a part of a region highly conserved from Xenopus to man. Non-SCLC cell line $\mathrm{H} 647$ has an intronic point mutation at the splice donor site which results in the incorporation of the entire intron 7 sequence into mRNA. This mutation leads to an undetectable amount of the p53 gene product, which could be due to rapid degradation of the truncated protein in $\mathrm{H} 647$, a phenomenon seen in other systems (20-22).

Defective products resulting from splicing mutations, which lead to a disease state, have been reported for the $\beta$-globin gene in $\beta$-thalassemia (20) and the hypoxanthine phosphoribosyl transferase gene in Lesch-Nyhan syndrome (23). Recently, intronic point mutations of the $\mathrm{Rb}$ gene have been found in five cases of retinoblastoma $(24,25)$, one bladder cancer cell line (26) and 1 SCLC cell line (27). In addition to the two mutations reported in detail here, we have found three other splicing mutations among 36 completely characterized p53 mutations in lung cancer $(5 / 36,14 \%)$ all of which change the amino acid sequence. These findings further support the premise that inactivation of p53 may play a role in the pathogenesis of lung cancer.

Since a mutant p53 gene can cooperate with an activated ras gene to transform primary rat embryo fibroblasts, it has been hypothesized that mutant p53 could act in a "dominant negative" fashion $(1,2)$. In fact, transgenic mice overexpressing mutant p53 have been shown to develop lung cancer (28). However, both $\mathrm{H} 526$ and $\mathrm{H} 647$ retain only a mutant allele in their genomes, consistent with the observations of frequent $17 p$ allele loss $(4,6)$. These observations suggest that a considerable fraction of p53 mutants may be entirely recessive and that complete loss of p53 function, which occurs by losing the remaining normal allele, is required to confer a selective growth advantage.

All p53 mutations so far examined appear to be the result of a somatic event $(5,8,10)$ (this study). However, the possibility exists that a fraction of lung cancer patients may be predisposed by inheriting or acquiring germ line mutations in the $\mathrm{p} 53, \mathrm{Rb}$ or other as yet unidentified tumor supressor genes (for review, see ref. 29). This study clearly indicates that we need to examine not only the exonic regions but also intronic sequences in searching for such a genetic predisposition.

\section{Acknowledgments}

We thank J. Broers and S. Jensen for help in immunocytochemistry; D. Ginsberg and H. Dosaka for valuable discussions and help in protein analysis; M. Nau for DNAs from the patient and reviewing the manuscript; D. S. Segal, D. Carbone for critical review of the manuscript. This work was supported in part by the G. Harold and Leila Y. Mathers Charitable Foundation. D. D'Amico is supported by Istituto di Fisiopatologia Respiratoria, C.N.R., of the Italian National Research Council.

\section{References}

1. Finlay, C., P. Hinds, and A. J. Levine. 1989. The p53 protooncogene can act as a suppressor of transformation. Cell. 57:1083-1093.

2. Eliyahu, D., D. Michalovitz, S. Eliyahu, O. Pinhasi-Kimhi, and M. Oren. 1989. Plasmids encoding wild type p53 can inhibit oncogene-mediated transformation. Proc. Natl. Acad. Sci. USA. 86:87638767.

3. Mowat, M., A. Cheng, N. Kimura, A. Berstein, and S. Benchimol. 1985. Rearrangements of the cellular p53 gene in erythroleukaemic cells transformed by Friend virus. Nature (Lond.). 314:633-636.

4. Yokota, J., M. Wada, Y. Shimosato, M. Terada, and T. Sugimura. 1987. Loss of heterozygosity on chromosomes 3, 13, 17 in small cell carcinoma and on chromosome 3 in adenocarcinoma of the lung. Proc. Natl. Acad. Sci. USA. 84:9252-9256.

5. Baker, S., E. Fearon, J. Nigro, S. Hamilton, A. Preisinger, J. Jessup, P. van Tuinen, D. Ledbetter, D. Barker, Y. Nakamura, R. White, and B. Vogelstein. 1989. Chromosome 17 deletions of p53 gene mutations in colorectal carcinomas. Science (Wash. DC). 244:217221 .

6. Weston, A., J. C. Willey, R. Modali, H. Sugimura, E. M. McDowell, J. Resau, B. Light, A. Haugen, D. L. Mann, B. F. Trump, and C. C. Harris. 1989. Differential DNA sequence deletions from chromosome 3, 11, 13 and 17 in squamous-cell carcinoma, large-cell carci- 
noma, and adenocarcinoma of the human lung. Proc. Natl. Acad. Sci. USA. 86:5099-5103.

7. Masuda, H., C. Miller, H. Koeffler, H. Battifora, and M. Cline. 1987. Rearrangement of the p53 gene in human osteogenic sarcomas. Proc. Natl. Acad. Sci. USA. 84:7716-7719.

8. Takahashi, T., M. M. Nau, I. Chiba, M. B. Birrer, R. K. Rosenberg, M. Vinocour, M. Levitt, H. Pass, A. F. Gazdar, and J. D. Minna 1989. p53: A frequent target for genetic abnormalities in lung cancer Science (Wash. DC). 246:491-494.

9. Ahujja, H., M. Bar-Eli, S. Advani, S. Benchimol and M. Cline. 1989. Alterations in the p53 gene and the clonal evolution of the blast crisis of chronic myelocytic leukemia. Proc. Natl. Acad. Sci. USA. 86:6783-6787.

10. Nigro, J., S. Baker, A. Preisinger, J. Jessup, R. Hostetter, K. Cleary, S. Bigner, N. Davidson, S. Baylin, P. Devilee, T. Glover, F. Collins, A. Weston, R. Modali, C. Harris, and B. Vogelstein. 1989. Mutations in the p53 gene occur in diverse human tumour types. Nature (Lond.). 342:705-708.

11. Carney, D. N., A. F. Gazdar, G. Bepler, J. G. Guccion, P. J. Marangos, T. W. Moody, M. H. Zweig, and J. D. Minna. 1985. Establishment and identification of small cell lung cancer cell lines having classic and variant features. Cancer Res. 45:2913-2923.

12. Brower, M., D. N. Carney, H. K. Oie, A. F. Gazdar, and J. D. Minna. 1986. Growth of cell lines and clinical specimens of human non-small cell lung cancer in a serum-free defined medium. Cancer Res. 46:798-806.

13. Nau, M., B. Brooks, J. Battey, E. Sausville, A. Gazdar, I. Kirsch, O. McBride, V. Bertness, G. Hollis, and J. Minna. 1985. L-myc, new myc- related gene amplified and expressed in human small cell lung cancer. Nature (Lond.). 318:69-73.

14. Lamb, P., and L. Crawford. 1986. Characterization of the human p53 gene. Mol. Cell. Biol. 6:1379-1385.

15. Hinds, P., C. Finlay, and A. Levine. 1989. Mutation is required to activate the p53 gene for cooperation with the ras oncogene and transformation. J. Virol. 63:739-746.

16. Banks, L., G. Matlashewski, and L. Crawford. 1986. Isolation of human-specific monoclonal antibodies and their use in the studies of human p53 expression. Eur. J. Biochem. 159:529-534.

17. Harlow, E., L. Crawford, D. Pim, and N. Williamson. 1981. Monoclonal antibodies specific for simian virus $\mathbf{4 0}$ tumor antigens. $J$. Virol. 39:861-869.

18. Wade-Evans, A., and J. Jenkins. 1985. Precise epitope mapping of the murine transformation-associated protein p53. EMBO (Eur. Mol. Biol. Organ.) J. 4:699-706.

19. Buchman, V., P. Chumakov, N. Ninkina, O. Samarina, and G.
Georgiev. 1988. A variation in the structure of the protein-coding region of the human p53 gene. Gene. 70:245-252.

20. Kazazian, H., S. Antonarakis, H. Youssoufian, C. Dowling, D. Philips, C. Wong, and C. Boehm. 1986. Comparison of deficiency allele of the $\beta$-globin and Factor VIII:C genes: New lessons from a giant gene. In Cold Spring Harbor Symp. Quant. Biol., Cold Spring Harbor Laboratory Press, New York. 371-379.

21. Hidaka, Y., T. Palella, T. O'Toole, S. Tarle, and W. Kelley. 1987. Human adenine phosphoribosyltransferase. Identification of allelic mutations at the nucleotide level as a cause of complete deficiency of the enzyme. J. Clin. Invest. 80:1409-1415.

22. Curiel, D., M. Brantly, E. Curiel, L. Sister, and R. G. Crystal. 1989. $\alpha 1$-antitrypsin deficiency caused by the $\alpha 1$-antitrypsin Null Mottawa gene. An insertion mutation rendering the $\alpha 1$-antitrypsin gene incapable of producing $\alpha 1$-antitrypsin. J. Clin. Invest. 83:11441152.

23. Gibbs, R., and C. Caskey. 1987. Identification and localization of mutations at the Lesch-Nyhan locus by ribonuclease A cleavage. Science (Wash. DC). 236:303-305.

24. Yandell, D., T. Campbell, S. Dayton, R. Petersen, D. Walton, J. Little, A. McConkie-Rosell, E. Buckley, and T. Dryja. 1989. Oncogenic point mutations in the human retinoblastoma gene: Their application to genetic counselling. N. Engl. J. Med. 321:1689-1695.

25. Dunn, J., R. Phillips, X. Zhu, A. Becker, and B. Gallie. 1989. Mutations in the RB1 gene and their effects on transcription. Mol. Cell Biol. 9:4596-4604.

26. Horowitz, J. H., D. W. Yandell, S. Park, S. Canning, P. Whyte, K. Buchkovich, E. Harlow, R. A. Weinberg, and T. P. Dryja. 1989. Point mutational inactivation of the retinoblastoma anti-oncogene. Science (Wash. DC). 243:937-940.

27. Horowitz, J., S.-H. Park, E. Bogenmann, J.-C. Cheng, D. Yandell, F. Kaye, J. Minna, T. Dryja, and R. Weinberg. 1990. Frequent inactivation of the retinoblastoma anti-oncogene is restricted to a subset of human tumor cells. Proc. Natl. Acad. Sci. USA. 87:2775-2779.

28. Lavigueur, A., V. Maltby, D. Mock, J. Rossant, T. Pawson, and A. Berstein. 1989. High incidence of lung, bone and lymphoid tumors in transgenic mice overexpressing mutant alleles of the p53 oncogene. Mol. Cell. Biol. 9:3982-3991.

29. Minna, J., F. Kaye, T. Takahashi, J. Harbour, R. Rosenberg, M. Nau, J. Whang-Peng, B. Johnson, M. Birrer, and A. Gazdar. 1989. Recessive oncogenes and chromosomal deletions in human lung cancer. In Recessive Oncogenes and Tumor Suppression. (Current Communications in Molecular Biology.) Cavenee, Hastie and Stanbridge, editors. Cold Spring Harbor Laboratory Press, New York. $57-65$. 